\title{
Fournier's gangrene: A review of contemporary management priorities
}

\author{
Mohammed Aldiwani ${ }^{1}$, Victor Palit ${ }^{2}$, Chandrashekhar Biyani ${ }^{2 *}$ and Sanjib Majumder ${ }^{3}$ \\ ${ }^{1}$ Imperial college NHS Trust, UK \\ ${ }^{2}$ St James's University Hospital, UK \\ ${ }^{3}$ Pinderfields Hospital, UK
}

\begin{abstract}
Fournier's gangrene was formally described in 1883 by Jean Alfred Fournier. It is a life-threatening condition characterised by necrotising polymicrobial infection of the perineal and genital region. Although relatively uncommon; prompt recognition and urgent debridement is key to control the infection and give the best chance of survival. Subsequent wound management ranges from healing by secondary intention for small areas, but most cases require reconstruction by plastic surgeons. Herein, we discuss a review of the contemporary information surrounding this condition.
\end{abstract}

\section{Introduction}

Fournier's gangrene (FG) is a life-threatening necrotising fasciitis of the perineal and genital region. Although Jean Alfred Fournier has been credited with first describing the condition in 1883 [1]; the first report of scrotal gangrene originates from a case described by Baurienne in $1764[2,3]$. Baurienne described the first debridement after a man was injured by the horns of an ox. He required more than one debridement and eventually recovered with the skin defect healing by secondary intention. In 1883, Fournier described rapidly progressing gangrenous infection of the genital area of otherwise healthy young men with unknown cause.

The term "Fournier's gangrene" is therefore somewhat confusing. Although Fournier's original description was idiopathic; more frequently, a cause can be identified [4]. This term now incorporates necrotising fasciitis of the genitalia of known aetiology in much older groups of patients with a more indolent onset [5]. The most common demographic is middle aged men between 50-60 years of age [6]. FG can occur in females although much less commonly; with a male to female ratio of 10:1 [7].

\section{Background}

\section{Anatomy}

FG is characterised by necrotising infection along the superficial perineal fascia (Colle's fascia). This fascia runs continuously with the dartos fascia of the genitalia and superiorly in the abdomen where it is known as Scarpa's fascia. Perineal infections can therefore extend towards these areas but will usually spare the deeper tissues including the testicles which have a separate direct blood supply from the aorta. Colle's fascia attaches posteriorly to the perineal body and so infections arising from the urogenital structures do not usually reach the anus. In contrast, anorectal infections usually breach the sphincteric musculature before reaching Colle's fascia and then spread anteriorly [8]. Due to the infective focus in the fascia layer, the skin appearances are often understated in comparison to the underlying tissue.

\section{Organisms}

Infection is polymicrobial and in most cases, a source can be identified from anorectal, genitourinary or skin commensal organisms. Bacterial cultures include a mixture of aerobes and anaerobes. Commonly implicated organisms include E. Coli; Proteus; Klebsiella; Bacteroides; Clostridium, Streptococci and Staphylococci. These organisms work synergistically producing accumulating toxins and thus inflicting rapid and devastating tissue damage.

\section{Causes}

The causes of infection are most commonly dermatological, urological or colorectal. Entry can result from direct trauma from the skin, as well as iatrogenic operative complications from any operation in the perineal region. Foreign bodies have also been implicated whether caused by a clinician or the patient. Urinary tract causes include urinary tract stone disease, urethral catheterisation, and renal abscess. Colorectal causes are described as the most common foci of infection in many case series' and include anorectal abscess, colorectal malignancy, inflammatory bowel disease and even intraabdominal sepsis from appendicitis or diverticulitits [5]. In women, anorectal causes are still the most common source however other female specific causes include genital abscess or post-operative complications [9]. When an obvious external source cannot be identified; it is advised to investigate for an abdominal source with cross sectional imaging such as Computed Tomography (CT). In some cases, no obvious cause is identified as per Fournier's initial description. It is important to recognise that comorbidity plays a significant causative role. Many patients who develop FG are afflicted with accompanying comorbidities including diabetes

${ }^{\star}$ Correspondence to: Chandrashekhar Biyani, St James's University Hospital, Leeds, UK, E-mail: shekharbiyani@hotmail.com

Key words: fournier's gangrene, necrotising fasciitis, urosepsis

Received: April 07, 2018; Accepted: April 23, 2018; Published: April 28, 2018 
mellitus (up to $60 \%$ of cases), obesity, alcoholism, immunosuppression; malnutrition and HIV which impairs the hosts ability to resist infection.

\section{Clinical presentation}

The diagnosis is based on clinical assessment. The classical signs of presentation are pain, swelling and erythema involving the perineum and scrotum. As gangrenous infection becomes established, the skin becomes dull, ischaemic and develops a purple discolouration as necrosis occurs (Figure 1). There may be a foul-smelling "dirty dishwasher" fluid discharge and crepitus may be felt on examination in $19-64 \%$ of patients [10]. The patient develops a systemic inflammatory response manifesting in fever, tachycardia and features of sepsis. The patient can rapidly become unwell, and often this may be disproportionate to the external skin appearances. The systemic septic shock can lead to multiorgan failure.

There may be a history of recent surgery or trauma. Any preceding symptoms may indicate an initial source of infection. Perianal pain, rectal bleeding may suggest a rectal source. A dermal source may start with cellulitis and oedema may indicate deeper fascial infections. Differential diagnoses to consider include cellulitis, localised abscess, epididymo-orchitis, idiopathic scrotal oedema and incarcerated inguinal hernia.

\section{Investigations}

A thorough examination of the abdomen, genitalia and perineum is necessary to confirm the diagnosis and detect a potential cause. Serum blood analysis, blood culture, urine culture and wound culture are all mandatory investigations. Leucocytosis, elevated serum creatinine, electrolyte imbalance, hyperglycaemia and anaemia can often be seen. The patient may develop coagulopathy and thrombocytopenia due to disseminated intravascular coagulopathy (DIC) [11].

\section{Imaging}

In unclear cases, radiological assessments can provide additional information. Ultrasound (US) of the scrotum can exclude testicular differential diagnoses. In cases of FG affecting the scrotum, ultrasonic features include thickening of the scrotal tissues and the presence of scattered echogenic foci representing gas [12]. Doppler flow studies can confirm flow to the testis. It is useful to recognise the potential features of US however it is should be used as an adjunct and has limited benefits.

Computerised Tomography (CT) is advocated as a more useful test with the ability to sensitively detect subcutaneous gas before it becomes

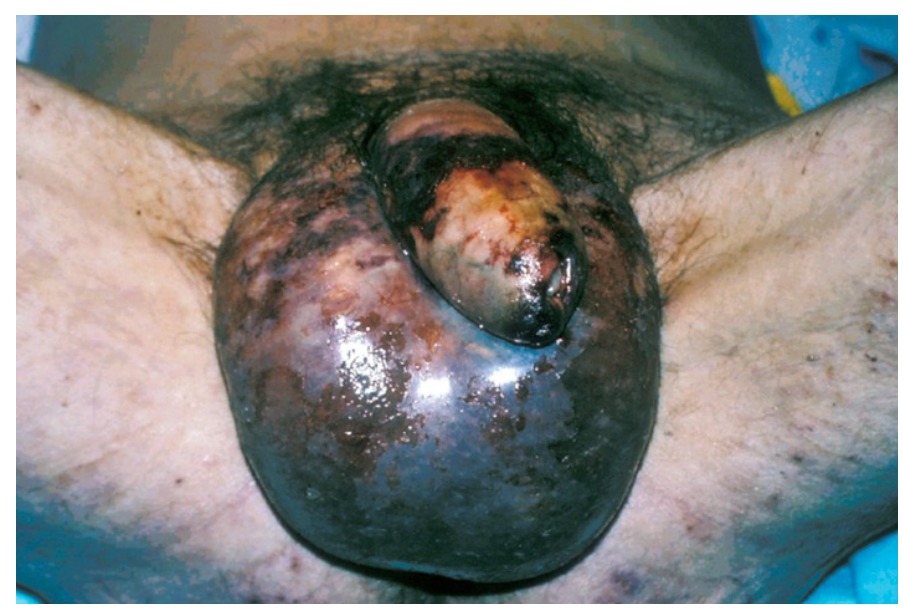

Figure 1. A classical presentation of Fournier's gangrene clinically palpable. CT also has the added benefit of intra-abdominal and retroperitoneal assessment which can be useful to delineate both a cause for FG as well as the extent of infiltration of the disease process. This can be helpful in planning the initial debridement or in the post treatment follow up setting to determine if further treatment is required. CT features include, subcutaneous gas, abscess collection and asymmetrical thickening along the fascial planes [6].

In cases where the diagnosis is unclear, a high index of suspicion is advised, and the patient taken to theatre for diagnostic debridement. The black, necrotic fascia with the tell-tale "dirty dishwater" fluid is pathognomic of necrotising fasciitis.

\section{Treatment}

Early recognition and prompt treatment is vital to maximise the chance of survival. The key principles for managing FG are resuscitation, broad spectrum antibiotics and surgical control. A multi-disciplinary approach between physicians, microbiologists, urologists, colorectal and plastic surgeons is important to aid correct decision making [13].

\section{Medical}

Urgent resuscitation with intravenous fluid replacement and correction of electrolyte abnormalities should be initiated. Broad spectrum empirical antibiotics should be commenced without delay. The choice of antibiotics may vary according to local policies and resistance patterns; but therapy should be aimed at targeting gram negative, gram positive and anaerobic organisms. Classically, a typical regimen may have consisted of penicillin, metronidazole and either a 3rd generation cephalosporin or aminoglycoside. Alternative antibiotic combinations can include clindamycin, fluoroquinolones or carbapenems. In such cases, it is useful to involve a microbiologist early with the management of such patients [14].

\section{Surgical}

Although antibiotics are essential to control the systemic dissemination and toxicity of organisms; they will not adequately treat the source of infection and so surgical management to remove necrotic tissue is a cornerstone in management [15].

Whenever necrotising infection has developed; prompt debridement is advocated. The following steps should be followed when taking a patient to theatre for initial debridement:

- Thorough examination under anaesthesia with the patient in lithotomy position to assess for a cause. This may include proctoscopy or cystoscopy

- Begin debridement from the obvious external skin abnormality and debride tissues until healthy well perfused viable tissue is identified.

- Adequacy of the initial debridement is paramount (Figure 2), and experience is required to recognise affected tissue; the skin overlying infected fascia may not necessarily look abnormal.

- Once the initial debridement is complete; the open wound should be irrigated, packed and left open with a view to a re-assessment +/repeat debridement after 24-48 hours.

- In cases where there is a lower urinary tract cause (usually urethra) then urinary diversion should be performed with a suprapubic catheter.

- In cases with extensive perineal debridement in the vicinity of the anus, faecal diversion should be considered via colostomy of faecal management system. 


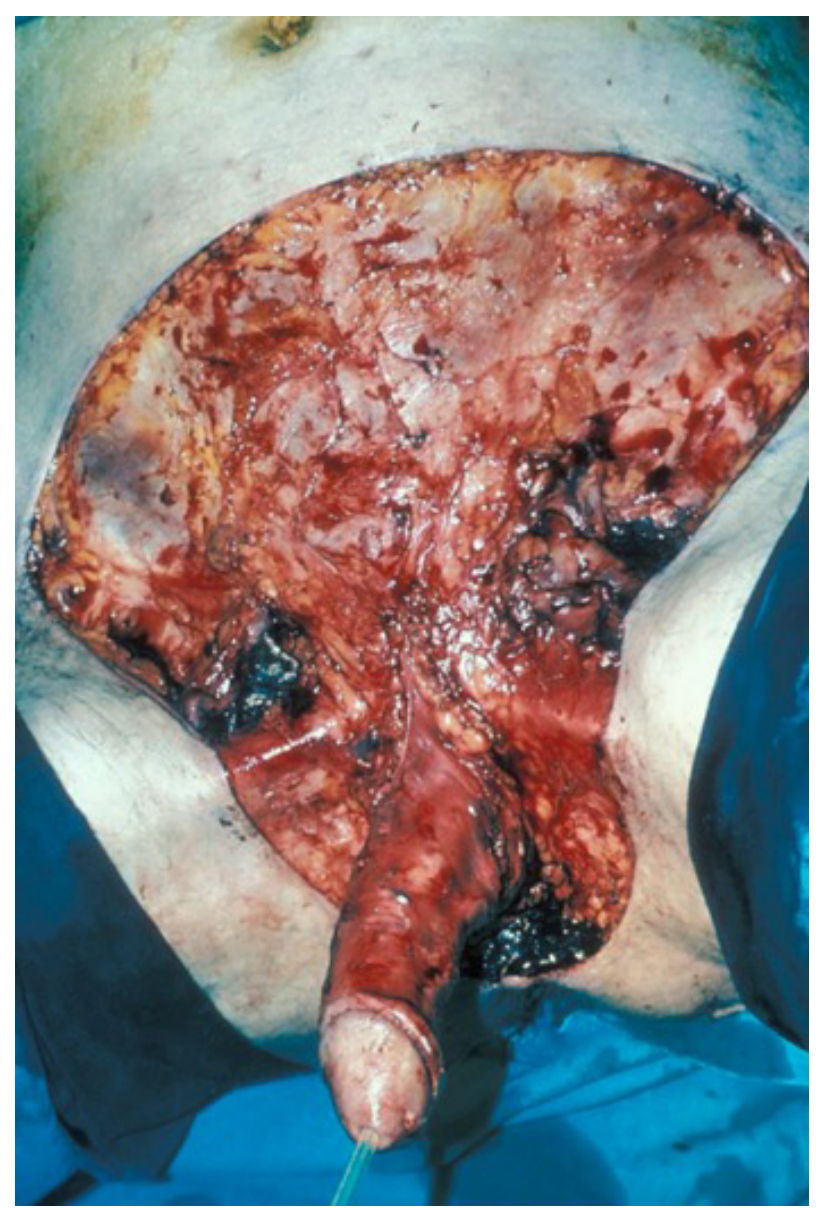

Figure 2. The same case as in figure 1, after the first debridement, demonstrating extent of fascial/skin involvement.

- If the scrotal tissues are removed, the testes can be protected initially in subcutaneous thigh pouch until definitive surgical reconstruction however this is NOT usually done at the first operation.

There is some debate as to the aggressiveness of initial debridement. Whilst the majority of published case series' advocate early and aggressive debridement to improve chance of survival [7,16-18]; others have noted no difference in outcome when performing more conservative debridement [19]. Similarly, there is some controversy surrounding the number of debridements required. Palmer et al. [20] observed no difference in the outcome where repeated debridements were performed whereas Chawla et al. [21] found that non-survivors had more numerous debridement (average 5.2) suggesting that inadequate initial debridement possibly played a role. It is difficult to provide adequate evidence to support either approach owing the wide heterogeneity of cases. It is logical to speculate that sicker patients with more extensive disease will require more debridements.

We advocate a radical initial debridement of all necrotic tissue, on the basis of published consensus and logical deduction that early control of the source of infection will positively impact the treatment of systemic toxicity.

\section{Diversion}

Diversion of faeces and urine must be considered. In some cases, it is a means of protecting open wounds from contamination, however it may be mandatory in some cases where the urethra, anus or rectum are directly involved in the initial infection. Urinary diversion can easily be achieved with urethral catheter where the urethra is normal or suprapubic catheter can be performed where there is primary urethral pathology.

Faecal diversion is controversial. In cases where there is direct anal sphincter involvement it may be mandatory to divert with a colostomy. In other cases, such as extensive perineal debridement with spared anal sphincter, alternative methods such as faecal management systems could be considered as an alternative. An example device is the FlexiSeal' faecal management system (FMS; Convatec, Rhymney, UK). This silicone catheter is inserted into the rectum and has a balloon for retention as well as an irrigation port. This has been successfully utilised in different groups of critically unwell patients including burns and FG. It is contra-indicated in case where this is a rectal neoplasm, injury or fistula [22]. Colostomy carries increased morbidity peri-operatively and post operatively. The FMS should be utilised in appropriate cases with to avoid stoma related morbidity, complications and the need for subsequent reversal [23].

\section{Wound Care}

After initial surgical debridement; a prolonged period of wound care is required to facilitate healing of tissues, prevention of secondary infection and preparation for reconstruction if necessary. Several adjuncts to standard wound care have been explored.

\section{Topical Negative Pressure (TNP) dressings}

TNP devices have become commonly utilised within a variety of complicated wounds. It was first introduced in 1997 by Argenta and Morykwas [24] and has been since successfully used to treat wounds in FG. TNP dressings are useful in managing the copiously exudative wounds in difficult areas that often result from debridement of FG. Patients and health care professionals show preference to TNP dressings compared to conventional dressings due to the reduced requirement for dressing changes, less pain, greater mobility and comparable cost [25]. However, TNP dressings should NOT be used until the infection is under control.

\section{Hyperbaric oxygen therapy (HBOT)}

The use of HBOT has been reported by several authors however results have been mixed. There are no good quality studies showing convincing benefit and this requires considerable resources not routinely available at most centres [26]. Its use can therefore not be recommended.

\section{Reconstruction}

In most cases, reconstruction is required. The mainstay of initial skin coverage, after the infection has been eradicated is the use of split thickness skin grafts (STSG) [27]. The use of TNP dressings are very useful to increase the "take" of the STSG, by ensuring the STSG is optimally adherent to the irregular contours of the perineum, and by reducing shearing of the STSG on patient movement (Figure 3).

The testes can be protected initially in subcutaneous thigh pouch until definitive surgical reconstruction. Further reconstruction to improve appearance is usually considered weeks or months once the patient has recovered fully from their life-threatening illness. Any of multiple techniques using tissue expansion, local, regional or even distant (free) flaps may be considered 


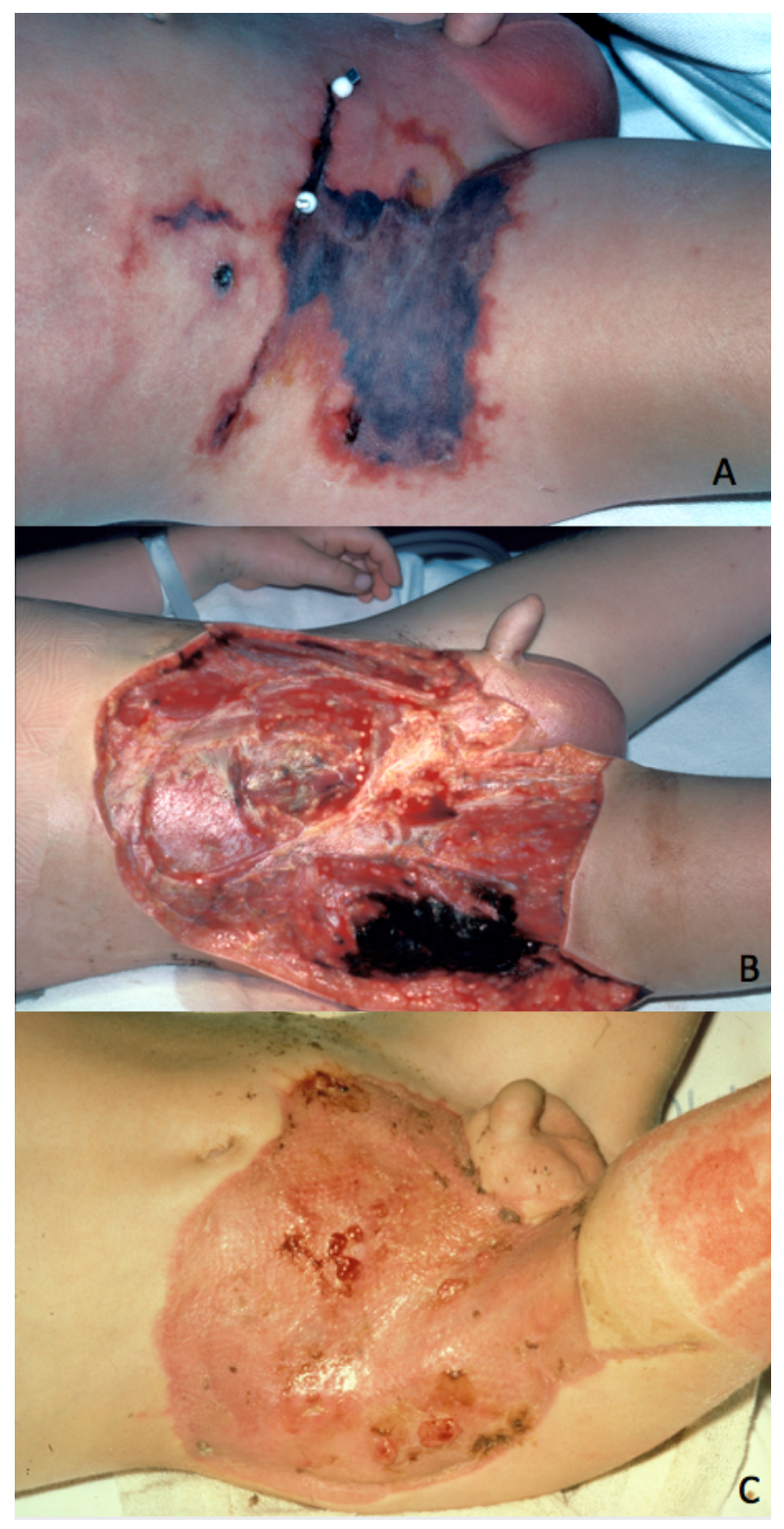

Figure 3. A case of Fournier's gangrene after appendicectomy incision (a) After excision, demonstrating extent of fascial/skin involvement (b), After soft tissue cover with split thickness skin graft [STSG] (c)

\section{Prognosis}

FG is a deadly condition with significant associated morbidity and mortality. Reported mortality varies between 3 to $45 \%$ worldwide; although a more representative average estimate is around $15 \%[6,27]$. The wide variation in these figures reflects patient cohorts from different parts of the world where aetiology varies. Anorectal causes have higher rates of mortality compared to urogenital and dermatological causes. Medical co-morbidity such as renal dysfunction, hepatic dysfunction and old age have worsening effect on mortality. In contrast, mortality from FG is lower in Africa and India where the source is more commonly dermatological and often affects younger groups of patients [28].

Laor et al. [29] devised the "Fourniers gangrene severity index" (FGSI) in an attempt to predict survival outcomes. They found that timing to first debridement, number of debridement's and involved surface area did not significantly correlate with survival. The most important factors in determining outcome related to the physiological status of the patient measured by the listed parameters in Table 1 . Where the FGSI was > 9; they observed a 75\% probability of death. This scoring tool has been utilised by multiple authors such as Kabay et al observed $96 \%$ chance of death where FGSI $>10.5$ and $96 \%$ chance of survival when $<10.5$ [16]. A modified Uludag FGSI has also been developed incorporating age and extent of gangrene [30]. Although this has shown to be similarly useful, it has not been shown to be more precise [31]. Key consistent predictors of mortality include the presence of acute kidney injury, coagulopathy and old age with comorbidities.

\section{Conclusions}

FG has evolved since its original description and tends to affect older age groups with increasing co-morbidity. Prompt recognition before physiological multi-organ dysfunction becomes established is the key to improving survival. In cases of uncertainty, CT can be a helpful adjunctive investigation to plan and ensure complete initial debridement. The mortality rates remain high and traditional methods of debridement remain the cornerstone of management. We advocate a thorough and complete initial debridement with a relook in 24-48 hours. In some cases, colostomy can be avoided with the use of faecal management systems however surgical diversion options need to be considered. Good post-operative wound care is important to prevent secondary infection and facilitate potential reconstruction. VAC therapy is a useful practical adjunct to facilitate these aims. A multidisciplinary approach between Physicians, Microbiologist, Urologists, Colorectal, and Plastic Surgeons is advocated to treat these challenging patients.

Table 1. The Fournier's Gangrene Severity Index

\begin{tabular}{|c|c|c|c|c|c|c|c|c|c|}
\hline \multirow{2}{*}{$\begin{array}{c}\text { Variables } \\
\text { Score }\end{array}$} & \multicolumn{4}{|c|}{ High abnormal values } & & \multicolumn{4}{|c|}{ Low abnormal values } \\
\hline & +4 & +3 & +2 & +1 & 0 & +1 & +2 & +3 & +4 \\
\hline Temperature, ${ }^{\circ} \mathrm{C}$ & $>41$ & $39-40.9$ & - & $38.5-35.9$ & $36-38.4$ & $34-35.9$ & $32-33.9$ & $30-31.9$ & $<29.9$ \\
\hline Heart rate & $>180$ & $140-179$ & $110-139$ & - & $70-109$ & - & $55-69$ & $40-54$ & $<39$ \\
\hline Respiration rate & $>50$ & $35-49$ & - & $25-34$ & $12-24$ & $10-11$ & $6-9$ & - & $<5$ \\
\hline Serum $\mathrm{Na}, \mathrm{mmol} / \mathrm{l}$ & $>180$ & $160-179$ & $155-159$ & $150-154$ & $130-149$ & - & $120-129$ & $111-119$ & $<110$ \\
\hline Serum $\mathrm{K}++, \mathrm{mmol} / 1$ & $>7$ & $6-6.9$ & - & $5.5-5.9$ & $3.5-5.4$ & $3-3.4$ & $2.5-2.9$ & - & $<2.5$ \\
\hline $\begin{array}{l}\text { Serum creatinine, } \mathrm{mg} / 100 \\
\mathrm{ml}, \times 2 \text { for acute renal failure }\end{array}$ & $>3.5$ & $2-3.4$ & $1.5-1.9$ & - & $0.6-1.4$ & - & $<0.6$ & - & - \\
\hline Hematocrit, $\%$ & $>60$ & - & $50-59.9$ & $46-49.4$ & $30-45.9$ & - & $20-29.9$ & - & $<20$ \\
\hline $\begin{array}{l}\text { White blood cell count, } \\
\text { total } / \mathrm{mm} 3 \times 1000\end{array}$ & $>40$ & - & $20-39.9$ & $15-19.9$ & $3-14.9$ & - & $1-2.9$ & - & $<1$ \\
\hline $\begin{array}{l}\text { Serum bicarbonate, venous, } \\
\mathrm{mmol} / \mathrm{l}\end{array}$ & $>52$ & $41-51.9$ & - & $32-40.9$ & $22-31.9$ & - & 18-21.9 & $15-17.9$ & $<15$ \\
\hline
\end{tabular}




\section{References}

1. Fournier AJ (1883) Gangrene foudroyante de la verge. Semaine Med 3: 345-8.

2. Medina PJ, González-Rivas FA, Blanco AM, Tejido SA, Leiva GO (2009) Historica review of Fournier's gangrene: Baurienne, 1764 and Herod the Great 4 BC. European Urology Supplements 8:121.

3. Baurienne H (1764) Sur une plaie contuse qui s' est terminee par le sphacele de le scrotum. J Med Chir Pharm 20: 251-6.

4. Kearney D (2011) Fournier's Gangrene: Diagnostic and Therapeutic Considerations. InGangrene-Current Concepts and Management Options. InTech.

5. Stephens BJ, Lathrop JC, Rice WT, Gruenberg JC (1993) Fournier's gangrene: historic (1764-1978) versus contemporary (1979-1988) differences in etiology and clinical importance. Am Surg 59: 149-154. [Crossref]

6. Levenson RB, Singh AK, Novelline RA (2008) Fournier gangrene: role of imaging. Radiographics 28: 519-28. [Crossref]

7. Eke N (2000) Fournier's gangrene: a review of 1726 cases. Br J Surg 87: 718-728. [Crossref]

8. Smith GL, Bunker CB, Dinneen MD (1998) Fournier's gangrene. Br J Urol 81: 347355. [Crossref]

9. Hasdemir AO, Büyükaşik O, Cöl C (2009) The clinical characteristics of female patients with Fournier's gangrene. Int Urogynecol J Pelvic Floor Dysfunct 20: 143943. [Crossref]

10. Bruketa T, Majerovic M, Augustin G (2015) Rectal cancer and Fournier's gangrenecurrent knowledge and therapeutic options. World J Gastroenterol 21: 9002. [Crossref]

11. Neary E (2005) A case of Fournier's gangrene. Trinity Student Medical Journal 6: 6872.

12. Uppot RN, Levy HM, Patel PH (2003) Case 54: Fournier gangrene. Radiology 226: 115-117. [Crossref]

13. Corman JM, Moody JA, Aronson WJ (1999) Fournier's gangrene in a modern surgical setting: improved survival with aggressive management. BJU Int 84: 85-8. [Crossref]

14. Mallikarjuna MN, Vijayakumar A, Patil VS, Shivswamy BS (2012) Fournier's Gangrene: Current Practices. ISRN Surg 2012: 942437. [Crossref]

15. Norton KS, Johnson LW, Perry T, Perry KH, Sehon JK, et al. (2002) Management of Fournier's gangrene: an eleven-year retrospective analysis of early recognition, diagnosis, and treatment. Am Surg 68: 709-713. [Crossref]

16. Singh G, Chawla S (2004) Aggressiveness - the key to a successful outcome in Fournier's gangrene. Med J Armed Forces India 60:142. [Crossref]
17. Kabay S, Yucel M, Yaylak F, Algin MC, Hacioglu A, et al. (2008) The clinical features of Fournier's gangrene and the predictivity of the Fournier's Gangrene Severity Index on the outcomes. Int Urol Nephrol 40: 997-1004. [Crossref]

18. Korkut M, Içöz G, Dayangaç M, Akgün E, Yeniay L, et al. (2003) Outcome analysis in patients with Fournier's gangrene: report of 45 cases. Dis Colon Rectum 46: 649-652. [Crossref]

19. Frezza EE, Atlas I (1999) Minimal debridement in the treatment of Fournier's gangrene. Am Surg 65: 1031-1034. [Crossref]

20. Palmer LS, Winter HI, Tolia BM, Reid RE, Laor E (1995) The limited impact of involved surface area and surgical debridement on survival in Fournier's gangrene. $\mathrm{Br}$ J Urol 76: 208-12. [Crossref]

21. Chawla SN, Gallop C, Mydlo JH (2003) Fournier's gangrene: an analysis of repeated surgical debridement. Eur Urol 43: 572-5. [Crossref]

22. Estrada O, Martinez I, Del Bas M, Salvans S, Hidalgo LA (2009) Rectal diversion without colostomy in Fournier's gangrene. Tech Coloproctol 13: 157-159. [Crossref]

23. Oguz A, Gumus M, Turkoglu A, Bozdag Z, Ulger BV, et al. (2015) Fournier's Gangrene: A Summary of 10 Years of Clinical Experience. Int Surg 100: 934-941. [Crossref]

24. Argenta LC, Morykwas MJ (1997) Vacuum-assisted closure: a new method for wound control and treatment: clinical experience. Ann Plast Surg 38:563-77. [Crossref]

25. Ozturk E, Ozguc H, Yilmazlar T (2009) The use of vacuum assisted closure therapy in the management of Fournier's gangrene. Am J Surg 197: 660-5. [Crossref]

26. Mindrup SR, Kealey GP, Fallon B (2005) Hyperbaric oxygen for the treatment of fournier's gangrene. J Urol 173: 1975-1977. [Crossref]

27. Koukouras D, Kallidonis P, Panagopoulos C, Al-Aown A, Athanasopoulos A, et al. (2011) Fournier's gangrene, a urologic and surgical emergency: presentation of a multiinstitutional experience with 45 cases. Urol Int 86: 167-172. [Crossref]

28. Eke N (1999) Fournier's gangrene, the Nigerian experience. Nig Postgrad Med J 6: 99-102.

29. Laor E, Palmer LS, Tolia BM, Reid RE, Winter HI (1995) Outcome prediction in patients with Fournier's gangrene. J Urol 154: 89-92. [Crossref]

30. Yilmazlar T, Ozturk E, Ozguc H, Ercan I, Vuruskan H, et al. (2010) Fournier's gangrene: an analysis of 80 patients and a novel scoring system. Tech Coloproctol 14: 217-223. [Crossref]

31. Roghmann F, von Bodman C, Löppenberg B, Hinkel A, Palisaar J (2012) Is there a need for the Fournier's gangrene severity index? Comparison of scoring systems for outcome prediction in patients with Fournier's gangrene. BJU international 110:135965. [Crossref]

Copyright: (C2018 Aldiwani M. This is an open-access article distributed under the terms of the Creative Commons Attribution License, which permits unrestricted use, distribution, and reproduction in any medium, provided the original author and source are credited. 